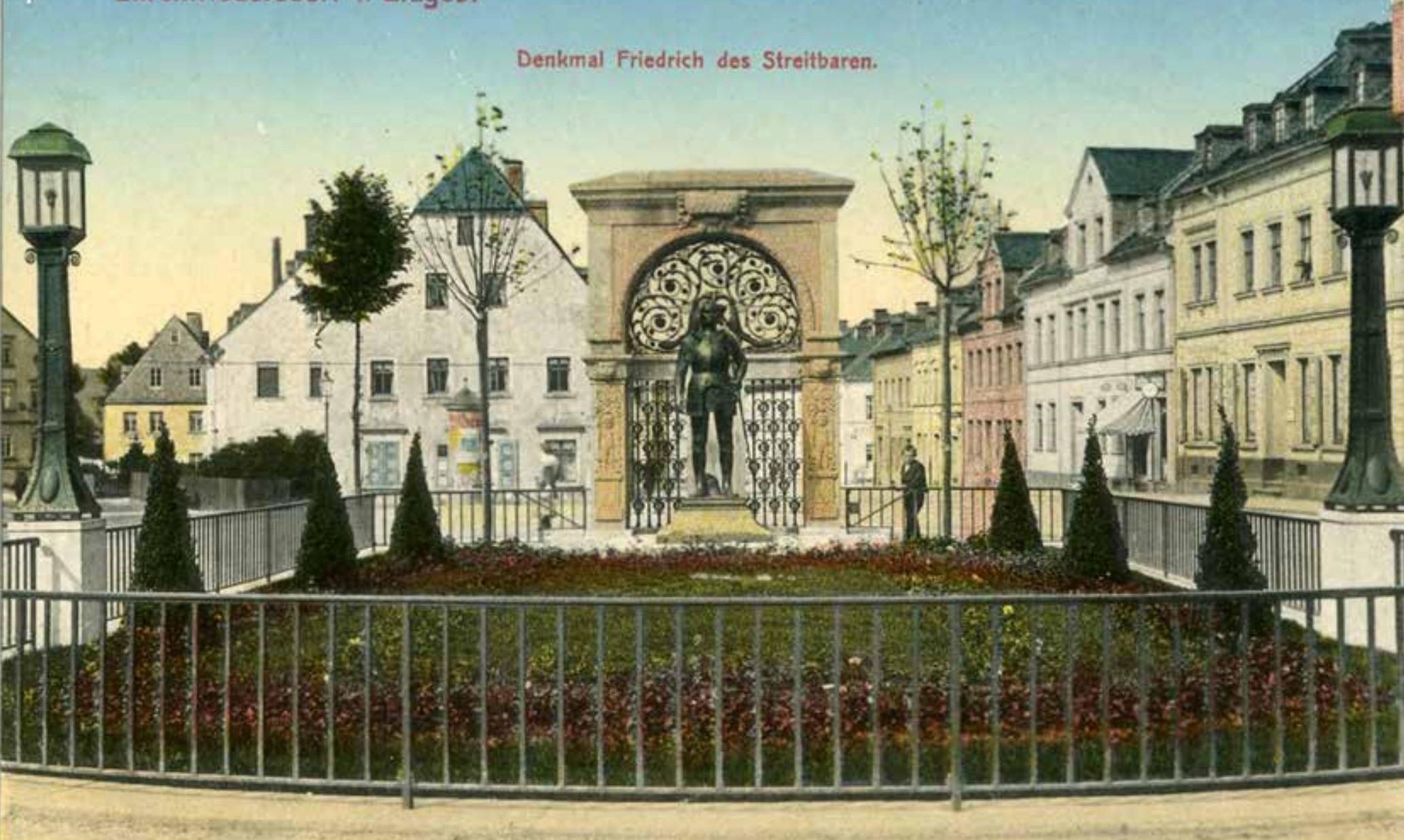

\title{
Friedrich der Streitbare und die Hussitenbewegung
}

\author{
Alexander Querengässer
}

Die Geschichte Sachsens, insbesondere jedoch die Biografie Markgraf Friedrichs IV. ist aufs Engste mit der hussitischen Bewegung in Böhmen verflochten. 1373 hatte Markgraf Wilhelm I., eine Verlobung Annas, der siebenjährigen Tochter Karls IV., mit seinem gerade einmal dreijährigen Neffen Friedrich vereinbart. Die einander Versprochenen lernten sich vermutlich nie kennen. 1382 wurde die Verbindung auf Veranlassung von Annas Bruder Wenzel gelöst. Die Luxemburgerin ehelichte anschließend den englischen König Richard II. ${ }^{1}$

Zur Gefolgschaft der neuen Königin gehörten auch Studenten der Universität Prag, die auf dem Inselkönigreich erstmals mit den Theorien des Kirchenreformers John Wyclif in Berührung kamen. Wyclif verurteilte den Verkauf kirchlicher Ämter und forderte die Unterstellung der Kirche unter den Staat. Den Anspruch des Papstes, Gottes Stellvertreter auf Erden zu sein, lehnte er ab. Darüber verurteilte er die
Verehrung von Heiligen und Reliquien. Wyclif starb 1384, nachdem er die Bibel ins Englische übersetzt hatte.

Jene der böhmischen Studenten, die nach einer Weile wieder nach Prag zurückkehrten, verbreiteten die Ideen Wyclifs an der dortigen Universität. Unter ihnen befand sich Hieronymus von Prag, der den jungen Magister Jan Hus damit vertraut machte. Hus schlug schließlich eine Karriere als Priester ein. Hieronymus reiste 1399 ein weiteres Mal nach England und kopierte mehrere Werke Wyclifs. Hus begann 1402 seine Tätigkeit als Prediger in der Prager Bethlehemkapelle. Auch er sprach zu seiner Gemeinde in der Landessprache. Dadurch verband sich die junge reformatorische früh mit der sich parallel entwickelnden tschechischen Nationalbewegung.

Diese spaltete zunehmend die Prager Universität. Hier fühlten sich die einheimischen Studenten benachteiligt, da ihre Nation nur über eine
Die Stadt Ehrenfriedersdorf im Erzgebirge würdigte Friedrich den Streitbaren, den ersten Kurfürsten von Sachsen aus der wettinischen Dynastie, 1907 mit einem Denkmal. Die Figur wurde im Zweiten Weltkrieg eingeschmolzen.

๑ Brück \& Sohn Kunstverlag Meißen 
1 Vgl.: Dieter Veldtrup: Zwischen Eherecht und Familienpolitik. Studien zu den dynastischen Heiratsprojekten Karls IV. Warendorf 1988, S. 425-427.

2 Hierzu Thomas Lang: Die Universität Leipzig. In: Jutta Charlotte von Bloh/Dirk Syndram/Brigitte Streich (Hrsg.): Mit Schwert und Kreuz zur Kurfürstenmacht. Friedrich der Streitbare, Markgraf von Meißen und Kurfürst von Sachsen (13701428). München 2007, S. 8897, hier S. 88-91; Enno Bünz: Die Gründung der Universität Leipzig 1409. In: Detlef Döring/Cecilie Hollberg (Hrsg.): Erleuchtung der Welt. Sachsen und der Beginn der modernen Wissenschaften. Dresden 2009, S. 24-35, hier S. 26.

3 Vgl. Lang (wie Anm. 2), S. 91-97; Bünz (wie Anm. 2), S. 31-34.

4 Zitiert nach Codex Diplomaticus Saxoniae I B 3, Nr. 220, S. 203; vgl. Siegfried Hoyer: Peter von Dresden und die Anfänge der Hussitenbewegung. In: Dresden im Mittelalter ( $=$ Dresdner Hefte 65/2001), S. 62-69; Mathias Meinhardt: Dresden und die Ketzerbewegung. In: Bloh/ Syndram/Streich (wie Anm. 2), S. 110-113.

5 Vgl. Hoyer (wie Anm. 4), S. 66-68.

6 Vgl. Enno Bünz: Drändorf (von, de Draindorff, Draendorff, de Slevin, von Schlieben), Johannes (Johann). In: Sächsische Biografie, hrsg. vom Institut für Sächsische Geschichte und Volkskunde e.V., bearb. von Martina Schattkowsky, Online-Ausgabe: http://www.isgv.de/ saebi/ (3.8.2016); Meinhardt (wie Anm. 4), S. 112.

7 Vgl. Hoyer (wie Anm. 4), S. 68.

8 Vgl. František Šmahel: Die Hussitische Revolution. Bd. 2, Hannover 2002, S. 878917; Heinz Rieder: Die Hussiten. Streiter für Glauben und Nation. Gernsbach 1998, S. 21-50; Josef Macek: Die Hussitische Revolutionäre Bewegung. Berlin 1958, S. 28-36; Ferdinand Seibt: Die Hussitische Revolution. In: Ferdinand Seibt: Hussitenstudien. München 1991, S. 79-96, hier S. 85-87.
Stimme verfügte, die drei „ausländischen“ Nationen hingegen über drei. Dies sollte sich ändern, als König Wenzel 1408 die Universität aufforderte, eine Gesandtschaft zum Konzil von Pisa zu entsenden. Dort hoffte er, das große Abendländische Schisma zu beenden und mit Alexander V. einen neuen Papst zu installieren, der ihm helfen sollte, die römische Königskrone wieder zu erlangen. Doch während die Böhmische Nation, angeführt von Hus, die Pläne des Königs unterstützte, stellten sich die drei anderen kategorisch dagegen. Daraufhin erließ Wenzel das Kuttenberger Dekret, womit er die Nationenverfassung der Universität umstürzte, der Böhmischen Nation drei Stimmen verlieh und die drei ausländischen in einer einzigen Nation mit nur einer Stimme zusammenfasste. Dieses Dekret und seine mit Waffengewalt erzwungene Durchsetzung führten zu einem Massenexodus von Studenten aus Prag. ${ }^{2}$

Eine große Gruppe dieser Studenten hatte bereits im Frühjahr 1409 Kontakt mit Markgraf Friedrich IV. von Meißen aufgenommen. Der Wettiner förderte die Ansiedlung der Studenten in seinem Herrschaftsgebiet. Bereits im Juni 1409 erreichte eine größere Gruppe Leipzig. Friedrich bemühte sich auf dem Konzil von Pisa um ein päpstliches Privileg zur Gründung einer Universität. Paradoxerweise war es Alexander V. - jener Papst, den die „ausländischen“ Prager Studenten nicht hatten unterstützen wollen der die Leipziger Universität mit allen Rechten und Privilegien ausstattete. Im Oktober 1409 nahmen die Fakultäten die Lehrtätigkeit auf. Friedrich förderte die Einrichtung erheblich und finanzierte zwanzig Magister aus seiner Kammerkasse. $^{3}$

Nicht alle Exilanten zog es nach Leipzig. Eine kleine Gruppe, zu der wohl auch ein Magister Peter gehörte, gelangte noch im selben Jahr nach Dresden. Dieser Magister Peter wurde bald darauf Rektor der Dresdner Kreuzschule. Einer seiner Schüler, Johannes Drändorf, erklärte später, dass ihm durch Magister Peter an der Dresdner Kreuzschule ein gegen die römisch-katholische Kirche gerichteter Kirchenbegriff gelehrt worden sei. Anscheinend versuchte Peter, den aus Prag kommenden Studenten die artes liberales zu vermitteln. Dagegen ging schließlich am 18. Oktober 1411 auch der frisch gewählte Meißner Bischof Rudolf von der Planitz vor. Er verbot allen Partikularschulen in seiner Diözese die Behandlung der Bibel oder kanonischer Rechtsbücher, da dies nur den Generalstudien erlaubt sei. Diese Maßnahme diente sicherlich nicht nur dem Schutz der Leipziger Universität, denn Rudolf drohte insbesondere der Dresdner Schule schwere Konsequenzen an („,et presertim Dres- den sub pena suspensionis ab ingressu ecclesie"). $^{4}$

Obwohl Peter in dieser Zeit nicht durch die Publikation kirchenkritischer Traktate bekannt geworden ist, verstand er das bischöfliche Dekret wohl als eine Drohung, denn er verließ Dresden wenig später. 1412 betrieb er in der Prager Neustadt eine Schule in der Burse „Zur schwarzen Rose“. Einige der hiesigen Schüler wurden später zu hussitischen Priestern geweiht. Peter von Dresden sympathisierte wohl mit der Bewegung, gehörte aber nicht zu ihren aktiven Köpfen. Er starb vermutlich 1425 in der Moldaumetropole. ${ }^{5}$

Zwei seiner Begleiter traten dagegen zeitig als Befürworter des ketzerischen Gedankenguts auf. Friedrich Eppinge hatte mit Peter von Dresden an der Kreuzschule gelehrt und in Prag wyclefistische Theorien verteidigt, die die Kirche als ketzerisch verurteilt hatte. Er starb allerdings bereits 1413. Nach ihm trat ein Nikolaus von Dresden - dessen Ursprünge ebenfalls im Dunkeln liegen - als Vordenker der kirchenkritischen Lehren auf. Er lehrte Wyclifs Theorien in deutscher Sprache. Zu seinen Schülern gehörte auch Johannes Drändorf, der Dresden 1411 verlassen hatte. 1424 kehrte er ins Reich zurück, um die hussitische Lehre zu verbreiten. Ein Jahr später wurde er in Heilbronn verhaftet und dem Bischof von Worms überstellt, der ihn der Ketzerei anklagen und am 17. Februar 1425 in Heidelberg verbrennen ließ. ${ }^{6}$

Es wäre sicherlich übertrieben, Dresden als ein deutsches Zentrum der frühen Hussitenbewegung zu bezeichnen. Dennoch lässt es sich nicht von der Hand weisen, dass von den hiesigen Gelehrten wichtige Impulse ausgingen. Nikolaus von Dresden gehörte früh einem radikalen Flügel der Bewegung an. 1416 verließ er Böhmen, sein weiteres Schicksal ist ungeklärt. Nach den Angaben des späteren hussitischen Theologen Jan Želivský kehrte er nach Meißen zurück und starb hier den Märtyrertot. ${ }^{7}$ Nikolaus und Peter standen in engem Kontakt zu Jakobellus von Mies. Drändorf deutete 1425 während seines Verhörs vor der Inquisition an, dass Peter bereits 1414 die Kommunion beiderlei Gestalt empfangen habe. Diese entwickelte sich bald zum zentralen Leitgedanken der hussitischen Bewegung. Die spätmittelalterliche Kirche erlaubte der Gemeinde beim Abendmahl nur das Brechen des Brots, nicht das Trinken des Weins. Das Blut Christi war nur den Priestern vorbehalten. Hus forderte - allerdings erst kurz vor seinem Tod - dass alle am Blut Christi teilhaben sollten. Die weitere Verbreitung dieser Idee wird vor allem Jakobellus von Mies und Nikolaus von Dresden zugeschrieben. ${ }^{8}$ 
Die böhmischen Reformideen hatten inzwischen längst internationale Aufmerksamkeit gewonnen. 1414 wurden Wyclifs Schriften auf dem Konzil von Konstanz erneut verboten. Um die Krone Böhmens von dem Vorwurf zu befreien, Häretiker zu unterstützen, lud König Sigismund Hus unter der Zusage freien Geleits nach Konstanz ein. Da er jedoch nicht zum Widerruf seiner Lehren bewegt werden konnte, wurde Hus am 6. Juli 1415 als Häretiker zum Feuertod verurteilt und am selben Nachmittag verbrannt. ${ }^{9}$

In Böhmen wurden die hussitischen Anhänger noch längere Zeit durch König Wenzel geschützt. Im Februar 1419 ließ dieser jedoch bis auf drei alle utraquistischen Kirchen in Prag schließen, woraufhin viele Priester in die übrigen böhmischen Städte abwanderten und dort ihre Lehren verbreiteten. Am 30. Juli stürmte eine erzürnte Gruppe Prager Bürger das Neustädter Rathaus, um inhaftierte Glaubensgenossen zu befreien. Der Streit eskalierte und die erzürnte Menge warf den Bürgermeister und etliches Ratspersonal aus dem Fenster. Dieser erste Prager Fenstersturz löste schließlich die hussitische Revolution aus. König Wenzel soll von diesen Vorgängen so geschockt gewesen sein, dass er einen Schlaganfall erlitt und am 16. August 1419 verstarb. ${ }^{10}$

Die hussitische Bewegung gewann im ganzen Land rasch an Boden. Sigismund von Luxemburg, der die Nachfolge seines verstorbenen Bruders antreten wollte, konnte sich nicht durchsetzen, da er nicht bereit war, die Forderung der Stände nach religiöser Anerkennung des Laienkelchs und Änderungen der Landesverfassung zugunsten der böhmischen Volksgruppen anzunehmen. In der Folge kam es zu bewaffneten Aufständen, an denen insbesondere ein neuer, radikalerer Zweig der Hussiten, die Taboriten, beteiligt gewesen war. Diese verbanden die hussitischen Ideen mit der Forderung nach Überwindung sozialer Standesgrenzen.

Da Sigismund der Rebellion aus eigener Kraft nicht mehr Herr werden konnte, bat er Papst Martin V. um Unterstützung. Dieser rief am 1. März 1420 die Heere Europas zum Kreuzzug gegen die böhmischen Ketzer auf. Wie groß das Kreuzzugsheer war, welches im Juni 1420 vor den Toren Prags erschien, lässt sich heute nur schwer rekonstruieren. Realistische Schätzungen gehen von höchstens 50.000 Mann aus. Auch Markgraf Friedrich war mit den meißnischen und thüringischen Aufgeboten nach Prag gezogen. ${ }^{11}$ Angeblich war er es selbst, der am 14. Juli 1420 den Angriff der meißnischen und schlesischen Kavallerie auf den östlich der Stadt gelegenen Veitsberg leitete. Hier hatten die
Hussiten einfache Holzbefestigungen errichtet, die von nur wenigen Männern unter der Führung Jan Žižkas von Trocnov verteidigt wurden. Doch die schwer gepanzerten Ritter waren nicht in der Lage, die Gräben und die dahinterliegenden Holzwände zu überwinden. Schließlich wurden sie von den Verteidigern der Stadt in der Flanke angegriffen. „Da sie in solchem Sturmlauf sich nicht halten konnten, stürzten viele vom hohen Felsen herab und brachen sich das Genick, und sehr viele wurden durch die Verfolger getötet" ${ }^{2}$, berichtet der böhmische Chronist Laurentius, der die Verluste der Kreuzfahrer mit 300 Mann angibt. Die Niederlage erschütterte die Moral des Heeres. Tag für Tag verließen mehr Ritter das Heerlager. Schließlich zog auch Sigismund, nachdem er sich am 28. Juli 1420 auf dem von königlichen Truppen gehaltenen Hradschin zum König von Böhmen hatte krönen lassen, aus Prag ab. Der erste Kreuzzug war gescheitert.
9 Vgl. Peter Hilsch: Johannes Hus. Prediger Gottes und Ketzer. Regensburg 1999, S. 30-53.

10 Vgl. František Palacký: Geschichte von Böhmen. Größtentheils nach Urkunden und Handschriften. Bd. 3, Abt. 2. Der Hussitenkrieg, von 1419-1431. Prag 1851, S. 47-50; Šmahel (wie Anm. 8), S. 1002-1020; Rieder (wie Anm. 8), S. 94-99.

Eine Buchmalerei aus dem Jenaer Kodex, entstanden um 1500, zeigt den Kampf der Hussiten

(links) gegen ein antihussitisches Heer. Die DDR verschenkte die Sammelhandschrift aus der Universitätsbibliothek Jena 1951 „zur Entschädigung für deutsches Unrecht" an die Tschechoslowakei.

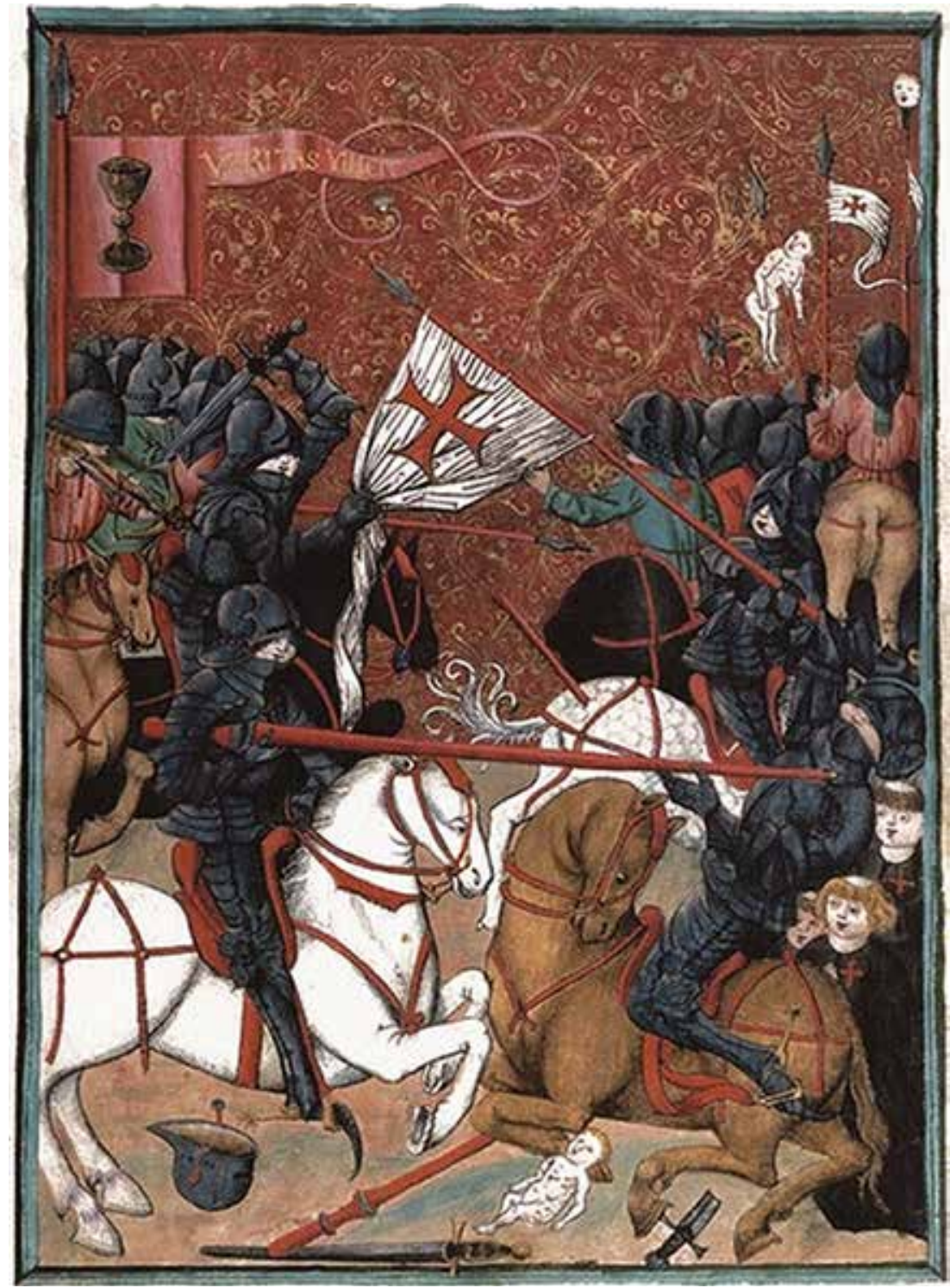


11 Vgl. Alexander Querengässer: Die Heere der Hussiten. Bd. 2. Hussitenkreuzzüge und Herrliche Heerfahrten. Berlin 2016, S. 4-8.

12 Zitiert nach Die Hussiten. Die Chronik des Laurentius von Brezová 1414-1421. Aus dem Lateinischen und Alttschechischen übersetzt, eingeleitet und erklärt von Josef Bujnoch. Graz/Wien/Köln 1988, S. 105.

13 Vgl. Palacký (wie Anm. 10), S. 206.

14 Vgl.: Palacký (wie Anm. 10), S. 246-249, 279-288; Šmahel (wie Anm. 8), S. 1200-1203; Meinhardt (wie Anm. 4), S. 117; Ernst Krocker: Sachsen und die Hussitenkriege. In: Neues Archiv für Sächsische Geschichte 21 (1900), S. 1-39, hier S. 5.

15 Vgl. Palacký (wie Anm. 10), S. 249-254; Krocker (wie Anm. 14), S. 5.

16 Vgl. Palacký (wie Anm. 10), S. 312-318; Friedrich von Bezold: König Sigismund und die Reichskriege gegen die Hussiten. Bd. 1. München 1872, S. 70-73; Krocker (wie Anm. 14), S. 5-6.

17 Zitiert nach Codex Diplomaticus Saxoniae I B 4, Nr. 244, S. 143-145, hier S. 144

18 Vgl. Codex Diplomaticus Saxoniae I B 4, Nr. 246, S. 146147. Zur Erlangung der Kurwürde vgl. Eckhardt Leisering: Die Belehungsurkunde von 1423 und 1425 im Spiegel der Ereignisse. In: Bloh/ Syndram/Streich (wie Anm. 2), S. 144-149.

19 Vgl. Codex Diplomaticus Saxoniae I B 4, Nr. 271, S. 165.

20 Dazu Otto Heuer: Der Bingener Kurverein 1424. In: Deutsche Zeitschrift für Geschichtswissenschaft 8 (1892), S. 207-225.

21 Vgl. Leisering (wie Anm. 18), S. 146-148; Jutta Charlotte von Bloh: Die öffentliche Belehnung 1425 in Ofen. In: Bloh/Syndram/Streich (wie Anm. 2), S. 150-158.

22 Zur Schlacht bei Aussig: Hubert Ermisch: Zur Geschichte der Schlacht bei Aussig. In: Neues Archiv für Sächsische Geschichte 47 (1926), S. 5-45; Alexander Querengässer: Triumph for the heretics. The Battle of Aussig 1426. In: Medieval Warfare 2 (2015), S. 42-46.
Die Hussiten festigten ihre Stellung im Land. In den ersten Monaten des Jahres 1421 errangen sie im Osten und Norden Böhmens eine Reihe kleinerer, aber wichtiger Erfolge. Im März eroberten sie die Stadt Komotau (Chomutov), wo sie anderthalb bis zweitausend Menschen abschlachteten. ${ }^{13}$

Sigismund hielt sich im Frühjahr 1421 in Leitmeritz (Litoměřice) und Brüx (Most) auf, um mit dem Kurfürsten von Brandenburg und den Markgrafen von Meißen einen neuen Feldzug vorzubereiten. Im Februar 1421 hatte der Reichstag in Nürnberg einen neuen Kreuzzug beschlossen. Demnach sollte das Reichsheer das Egertal hinab ins böhmische Becken ziehen und sich mit den Truppen Friedrichs des Streitbaren vereinigen. Die Aufstellung dieser Heere kostete jedoch wertvolle Zeit. Erst im späten Sommer standen sie bereit. Friedrich IV. zog im August mit einem meißnisch-thüringischen Heer über das Erzgebirge, um die von den Hussiten belagerte Stadt Brüx zu entsetzen. Am 5 . August errang der Markgraf einen der wenigen Schlachterfolge über die böhmischen Ketzer. Als die Hussiten das meißnische Heer heran marschieren sahen, verließen sie unvorsichtiger Weise ihre Wagenburg und stellten sich zur offenen Feldschlacht. Hier waren sie den gut ausgerüsteten Rittern unterlegen und wurden schwer geschlagen. ${ }^{14}$

Trotz dieses Anfangserfolges endete auch der zweite Kreuzzug mit einem Fehlschlag. Friedrichs Heer vereinte sich Mitte September mit dem Reichsheer, dass die kleine Stadt Saaz (Žatec) belagerte. Hier zerstritten sich die fürstlichen Führer. Friedrich drängte darauf, die Stadt, die hartnäckigen Widerstand leistete, links liegen zu lassen und auf Prag zu ziehen, was der Kurfürst von der Pfalz jedoch ablehnte. Die Verluste der Belagerer wuchsen so stark an, dass sich die Heerführer schließlich darauf beschränkten, die Stadt auszuhungern und das Umland auszuplündern. Das Heer zerbröckelte, täglich zogen mehr Ritter und Knechte in die Heimat ab. Schließlich war es so geschwächt, dass auch der Pfälzer auf die Nachricht vom Anmarsch Jan Žižkas für einen sofortigen Rückzug plädierte. Als das Kreuzfahrerheer sein Lager verbrannte, machte die Besatzung von Saaz einen Ausfall. Die Hussiten machten mehrere Hundert Gefangene und erbeuteten etliches Kriegsgerät. ${ }^{15}$

Der 1422 gestartete dritte Kreuzzug hatte bereits mehr den Charakter einer Entsatzaktion als eines Unterwerfungsfeldzuges. Das Heer unter Friedrich I. von Brandenburg, welches hierfür zusammengestellt wurde, sollte die königliche Burg Karlstein nördlich von Prag entsetzen.
Allerdings hatten sowohl der Brandenburger, als auch Friedrich IV., der seine Truppen erneut über das Erzgebirge heran führen sollte, Probleme, ihre Reihen zu füllen. Das Reichsheer rückte schließlich Anfang Oktober in Böhmen ein, war jedoch viel zu schwach, um den Karlstein $\mathrm{zu}$ entsetzen. Friedrich IV. war nicht in der Lage, sich an dem Feldzug zu beteiligen, da in seinem Heer eine Seuche ausgebrochen war. Das Reichsheer zerstritt sich und verließ Böhmen, ohne den Karlstein erreicht zu haben, dessen Besatzung am 8. November mit den Hussiten einen Waffenstillstand abschloss. ${ }^{16}$

Trotz der wiederholten Fehlschläge war Sigismund gezwungen, die Kriegsleistungen der großen Reichsfürsten entsprechend zu entlohnen. Insbesondere Friedrich profitierte von seinen Feldzügen. Noch 1422 wurde er mit mehreren Schlössern im Vogtland belehnt, und als im November diesen Jahres der letzte askanische Kurfürst von Sachsen starb, eröffnete sich dem Wettiner Gelegenheit, in die Elite der KurReichsfürsten vorzustoßen. Am 6. Januar 1423 übertrug Sigismund „angesehen solich geneme true und dinste, die uns der hochgeborn Fridrich lantgrave $\mathrm{zu}$ Duringen und marggrave $\mathrm{zu}$ Myßen der ellter unser lieber oheim und fürste offt und dicke lieblich erczeigt und getan hat, teglich tut und furbaz tun sol und mag in kunftigen ziten"17 das Herzogtum und die Kurwürde von Sachsen. Am gleichen Tag schloss Sigismund mit Friedrich ein neues Bündnis ab. ${ }^{18}$ Später verpfändete er ihm auch noch die böhmischen Städte Brüx und Aussig (Ústí nad Labem). ${ }^{19}$

Hatte Sigismund sich ein energisches Vorgehen der Reichsfürsten gegen die Hussiten gewünscht, so wurde er bitter enttäuscht. Die Kurfürsten warfen dem König eine Vernachlässigung der Reichspolitik und auch mangelnde Konsequenz im Vorgehen gegen die Hussiten vor und schlossen im Januar 1424 die gegen den Luxemburger gerichtete „Bingener Einung“ ab. ${ }^{20}$ In der Folge gelang es dem König allerdings, Schlesien und auch Polen-Litauen im Kampf gegen die Böhmen auf seine Seite zu ziehen. 1425 reiste Friedrich persönlich nach Ungarn. Er erneuerte er sein Bündnis mit dem König, wofür er am 1. August 1425 in Ofen (Buda) feierlich mit dem Kurfürstentum Sachsen belehnt wurde. ${ }^{21}$

An seine alten militärischen Erfolge konnte der neuernannte Kurfürst indessen nicht anknüpfen. Auf einer Reise zum Nürnberger Reichstag 1426 erhielt er die Nachricht von der katastrophalen Niederlage eines sächsisch-thüringischen Heeres in der Schlacht bei Aussig. Den Hussiten war es gelungen, all ihre Feldheere zu 


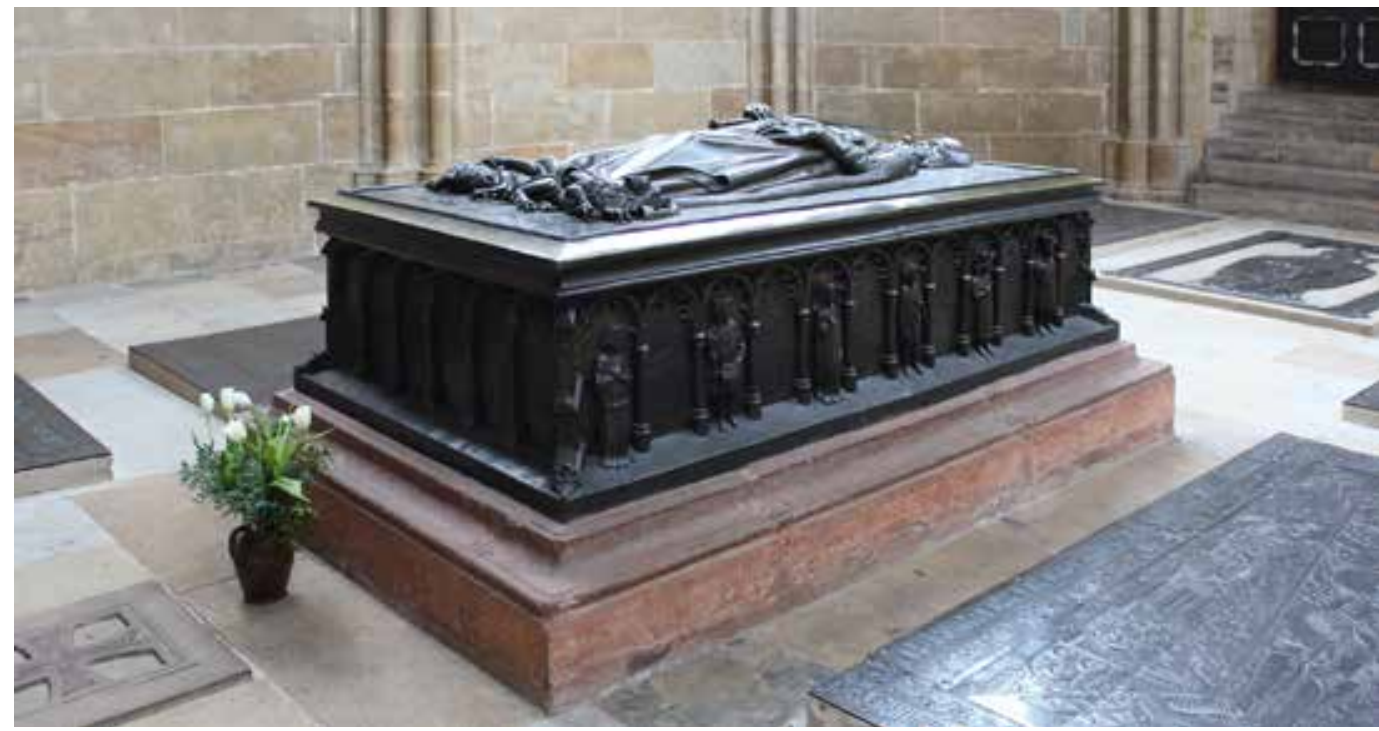

vereinen und die an Friedrich verpfändete Stadt zu belagern. Das Heer, welches die Kurfürstin daraufhin zum Entsatz ausschickte, scheiterte am 16. Juni beim Sturm auf die Wagenburg der Ketzer. Schätzungsweise 2.000 bis 4.000 Ritter und Knechte wurden auf der anschließenden Flucht erschlagen. Aussig fiel einen Tag später. ${ }^{22}$ In Sachsen bereitete die Kurfürstin eine Verteidigung von Königstein, Pirna, Freiberg und Dresden vor, aber noch immer wagten sich die Hussiten nicht über das Erzgebirge. Als Friedrich aus Nürnberg zurückkehrte, mobilisierte er sogleich ein neues Heer. Immerhin hielt Brüx der hussitischen Belagerung weiterhin stand. Tatsächlich zog der Kurfürst nur acht Wochen nach der Katastrophe von Aussig nach Böhmen und schlug das Prager Feldheer zurück, welches dabei 1.500 Mann auf dem Feld zurückließ.23

Nach der schweren Niederlage des sächsischen Heeres in der Schlacht bei Aussig nahm die Auseinandersetzung mit den Hussiten neue Züge an. Friedrich konnte seinen Anspruch auf die nordböhmischen Städte nicht weiter verfolgen. Am vierten Kreuzzug 1427 nahm der Kurfürst krankheitsbedingt nicht mehr aktiv teil. Stattdessen sandte er seinen Sohn mit nur wenigen Rittern zum Reichsheer nach Nürnberg. ${ }^{24}$

Am 4. Januar 1428 starb Friedrich I. Sein Nachfolger Friedrich II. sah sich im Winter 1429/30 einer großangelegten hussitischen Invasion gegenüber. Die „herrliche Heerfahrt“, die weite Teile Sachsens verwüstete, war jedoch ein Raub- und kein Eroberungsfeldzug. Über die osterzgebirgischen Pässe marschierten die Hussiten in der Mark Meißen ein. Sie drangen bis Leipzig vor, wagten jedoch keinen Sturm auf die starken Mauern der Stadt, in der sich das kurfürstliche Heer verschanzt hielt. Stattdessen plünderten sie Altenburg und fielen anschlie-

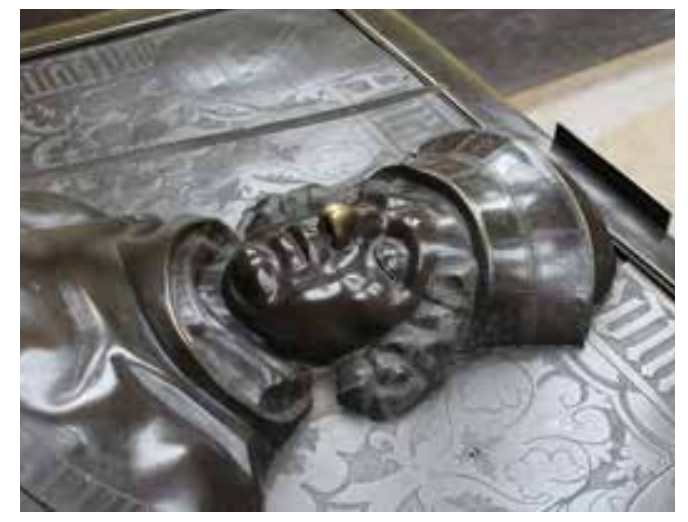

ßend in Franken ein. ${ }^{25}$ Die Verheerungen dieses Raubzugs und die Eindrücke eines weiteren erfolglosen Kreuzzuges 1431 führten schließlich dazu, dass Kurfürst Friedrich II. am 4. August 1431 im nordböhmischen Friedstein einen zweijährigen Friedensvertrag mit den Taboriten abschloss. ${ }^{26}$

In die Zeit dieses Friedens fällt die entscheidende Niederlage der radikalen Hussiten in der Schlacht bei Lipan am 30. Mai 1434. Im Anschluss gelang es Sigismund, einen Ausgleich mit den gemäßigten Utraquisten herzustellen. Nach dem Ablauf des Friedsteiner Friedens rückte auch Friedrich II. mit einem Heer in Nordböhmen ein. Er vereinigte sich mit den Truppen des Kaisers. Zusammen gelang es ihnen, den Radikalen am 23. September 1434 bei Brüx eine weitere schwere Niederlage beizubringen. ${ }^{27}$

In der Folgezeit konnte Sigismund seine Herrschaft in Böhmen weiter absichern. Im Juli 1436 erkannten die Utraquisten auf dem Iglauer Landtag die Prager Kompaktakten an. Einen Monat später zog Sigismund als unangefochtener böhmischer König in Prag ein und erklärte wenig später die hussitische Rebellion für beendet. $^{28}$
Grabtumba für Kurfürst

Friedrich den Streitbaren in der Fürstenkapelle des Meißner Doms um 1435

Foto: Matthias Donath,

Idealporträt Friedrichs des Streitbaren von der Grabtumba im Meißner Dom

Foto: Matthias Donath

23 Vgl. Palacký (wie Anm. 10), S. 417-419; Krocker (wie Anm. 14) S. 23-24; Bezold (wie Anm. 16), S. 85.

24 Vgl. Krocker (wie Anm. 14), S. 26-28

$25 \mathrm{Zu}$ diesem Feldzug ausführlich: Ralph Gundram: Döbeln und die Hussiten. Der hussitische Feldzug 1429/30 zwischen Elbe und Mulde in Legende und Wirklichkeit. In: Neues Archiv für Sächsische Geschichte 79 (2008), S. 1-26; Thomas Krzenck: Die Hussitenkriege, Sachsen und Leipzig. In: Ulrich von Hehl (Hrsg.): Stadt und Krieg. Leipzig in militärischen Konflikten vom Mittelalter bis ins 20. Jahrhundert. Leipzig 2015, S. 51-69.

26 Vgl. Krocker (wie Anm. 14), S. 29-37.

27 Vgl. Querengässer (wie Anm. 11), S. 55-58.

28 Vgl. Šmahel (wie Anm. 8), S. 1622-1640.

\section{Autor}

Dr. Alexander Querengässer Leipzig 